\title{
Seasonal Modes of Surface Cooling in the Gulf of Guinea
}

\author{
JULIEN JOUANNO \\ Université de Toulouse, UPS, and IRD, LEGOS, Toulouse, France, and Departamento de Oceanografía Física, \\ CICESE, Ensenada, Baja California, Mexico \\ FRÉdÉRIC MARIN AND YVES DU PENHOAT \\ Université de Toulouse, UPS, and IRD, LEGOS, Toulouse, France \\ JEAN MARC MOLINeS \\ MEOM, LEGI-CNRS, Grenoble, France \\ JULIO SHEINBAUM \\ Departamento de Oceanografía Física, CICESE, Ensenada, Baja California, Mexico
}

(Manuscript received 25 January 2011, in final form 6 April 2011)

\begin{abstract}
A numerical simulation of the tropical Atlantic Ocean indicates that surface cooling in upwelling zones of the Gulf of Guinea is mostly due to vertical mixing. At the seasonal scale, the spatial structure and the time variability of the northern and southern branches of the South Equatorial Current (SEC), and of the Guinea Current, are correlated with the timing and distribution of turbulent heat fluxes in the Gulf of Guinea. Through modulation of the velocity shear at the subsurface, these surface currents control the vertical turbulent exchanges, bringing cold and nutrient-rich waters to the surface. This mechanism explains the seasonality and spatial distribution of surface chlorophyll concentrations better than the generally accepted hypothesis that thermocline movements control the nutrient flux. The position of the southern SEC explains why the cold tongue and high chlorophyll concentrations extend from the equator to $4^{\circ} \mathrm{S}$ in the southeastern part of the basin.
\end{abstract}

\section{Introduction}

The largest seasonal fluctuations of sea surface temperature (SST) in the tropical Atlantic Ocean occur in the Gulf of Guinea. The most characteristic feature is the seasonal appearance of a tongue of cool SST east of $20^{\circ} \mathrm{W}$, along and south of the equator (Carton and Zhou 1997). Between April and August, temperatures at the equator drop from more than $28^{\circ} \mathrm{C}$ to less than $23^{\circ} \mathrm{C}$. During the same period, a strong cooling event occurs along the northern coast of the Gulf of Guinea (Bakun 1978). A secondary cooling of lower duration, intensity, and extent exists in these two regions. It peaks in November-December at the equator (Okumura and Xie

Corresponding author address: Julien Jouanno, Oceanografia Fisica, CICESE, Km 107 Carr. Tijuana-Ensenada, 22860, Ensenada, Baja California, Mexico.

E-mail: jouanno@cicese.mx
2006) and in January-February along the northern coast (Picaut 1983). It has been proposed that the semiannual cycle at the equator is due to a semiannual cycle of surface current divergence (Helber et al. 2007) or thermocline shoaling (Okumura and Xie 2006) as a consequence of local and remote wind forcing. However, recently observational and model studies have provided evidence that vertical mixing could play an important role right at the equator (Foltz et al. 2003; Peter et al. 2006; Jouanno et al. 2011, manuscript submitted to J. Geophys. Res.). Cooling along the northern coast has been correlated with the intensification of the Guinea Current but not with the local wind stress (Bakun 1978). Picaut (1983) suggested that remote wind forcing affects the coastal SSTs through the poleward propagation of a coastal trapped wave originating at the equator. But the mechanism causing the cooling is still uncertain.

Chlorophyll- $a$ (Chl-a) concentrations in the Gulf of Guinea follow the seasonal and spatial variations of the 
a) SST (degC) during August in model (colors) \& observations

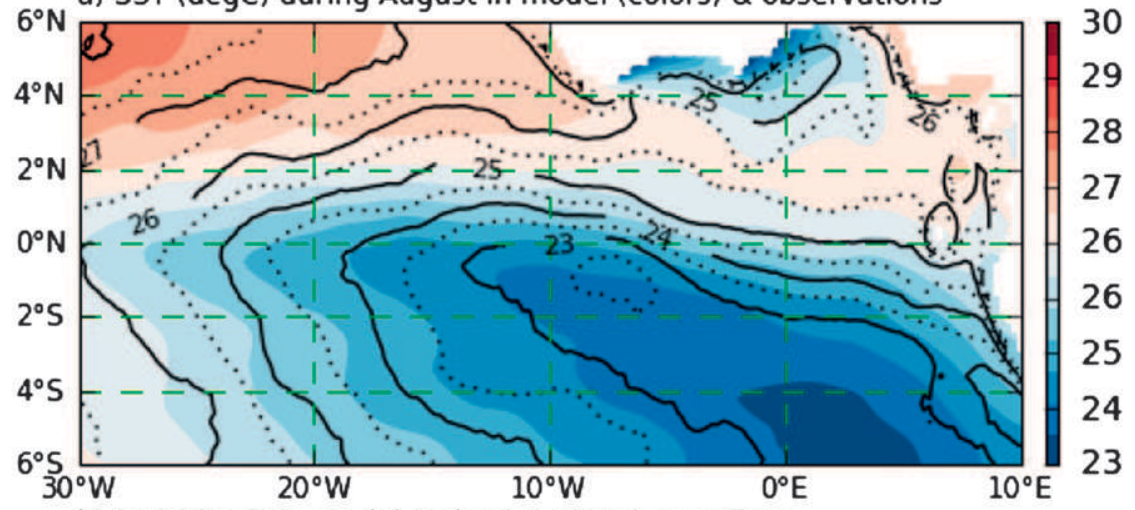

b) SST (degC) in model (colors) \& TMI observations

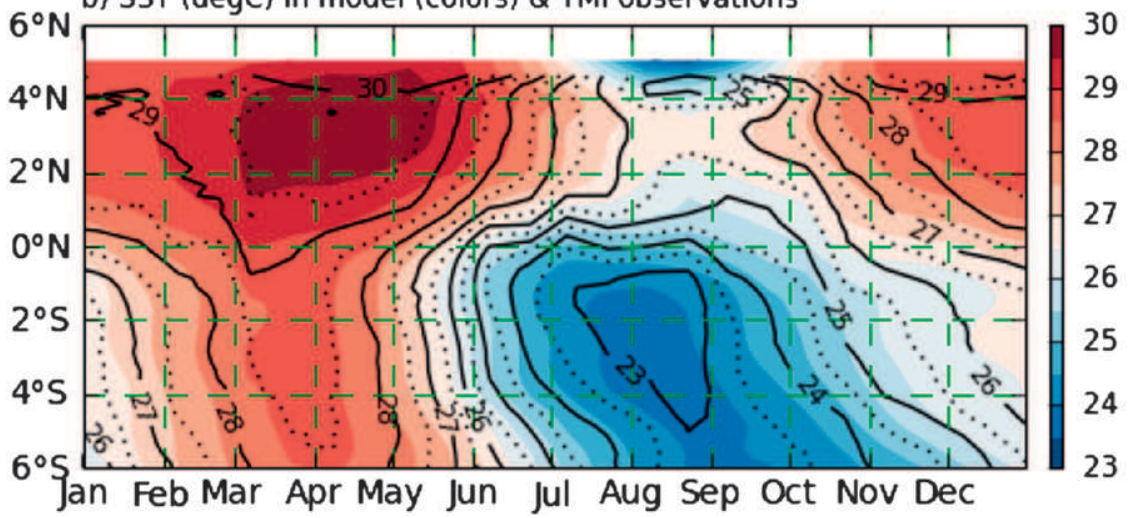

FIG. 1. Mean climatological SST $\left({ }^{\circ} \mathrm{C}\right)$ : (a) horizontal distribution in August and (b) timelatitude distribution at $5^{\circ} \mathrm{W}$, for the model (colors) and satellite TMI observations (contours). Interval between contours is $0.5^{\circ} \mathrm{C}$ (solid lines for integer values, dotted lines otherwise). The considered period is $2001-06$.

seasonal SST (Grodsky et al. 2008). This suggests that a common process brings cool and nutrient-rich waters to the surface. It is generally proposed that the seasonal uplift of the thermocline combined with mixing by local winds is the principal mechanism controlling vertical nutrient fluxes and phytoplankton blooms (Signorini et al. 1999; Grodsky et al. 2008). The goal of the present paper is to demonstrate from a realistic numerical simulation that the seasonal variability of vertical mixing in the upper eastern equatorial Atlantic, resulting from the variability in surface currents, controls the seasonal cycle of both surface cooling and Chl-a distribution.

\section{Model and data}

The model configuration is a subdomain $\left(20^{\circ} \mathrm{S}-20^{\circ} \mathrm{N}\right.$, $\left.60^{\circ} \mathrm{W}-15^{\circ} \mathrm{E}\right)$ of the state-of-the-art global $1 / 4^{\circ}$ model ORCA025-G70 from the DRAKKAR project (Barnier et al. 2006). It is based on the ocean general circulation model Nucleus for European Models of the Ocean (NEMO; Madec 2008). Radiative conditions are used at the open boundaries of the model, relaxing model variables to 5-day averages of outputs from the global interannual experiment ORCA025-G70 and radiating perturbations outward. The vertical turbulent mixing is parameterized using a level-1.5 turbulence closure scheme (Blanke and Delecluse 1993). The atmospheric fluxes of momentum, heat, and freshwater are provided by bulk formulas and an interannual forcing dataset (Brodeau et al. 2010), which is a combination of 40-yr European Centre for Medium-Range Weather Forecasts (ECMWF) Re-Analysis (ERA-40) data (6-h fields of wind, atmospheric temperature, and humidity) and satellite observations (daily fields of longwave and shortwave radiation; monthly fields of precipitation). The model was integrated over the period 1979-2007. Daily averages from 2001 to 2006 are used in the present analysis.

Daily turbulent heat fluxes are computed at each depth $z$ of the model as

$$
Q_{\mathrm{zdf}}=\rho_{0} C_{p} \int_{-z}^{0} \partial_{z}\left(K_{z} \partial_{z} T\right) d z
$$

where $\rho_{0}$ is the water density, $C_{p}$ the specific heat, $K_{z}$ the vertical diffusion coefficient for tracers, and $\partial_{z} T$ the 
a) MLT tendency (degC/day) - Net

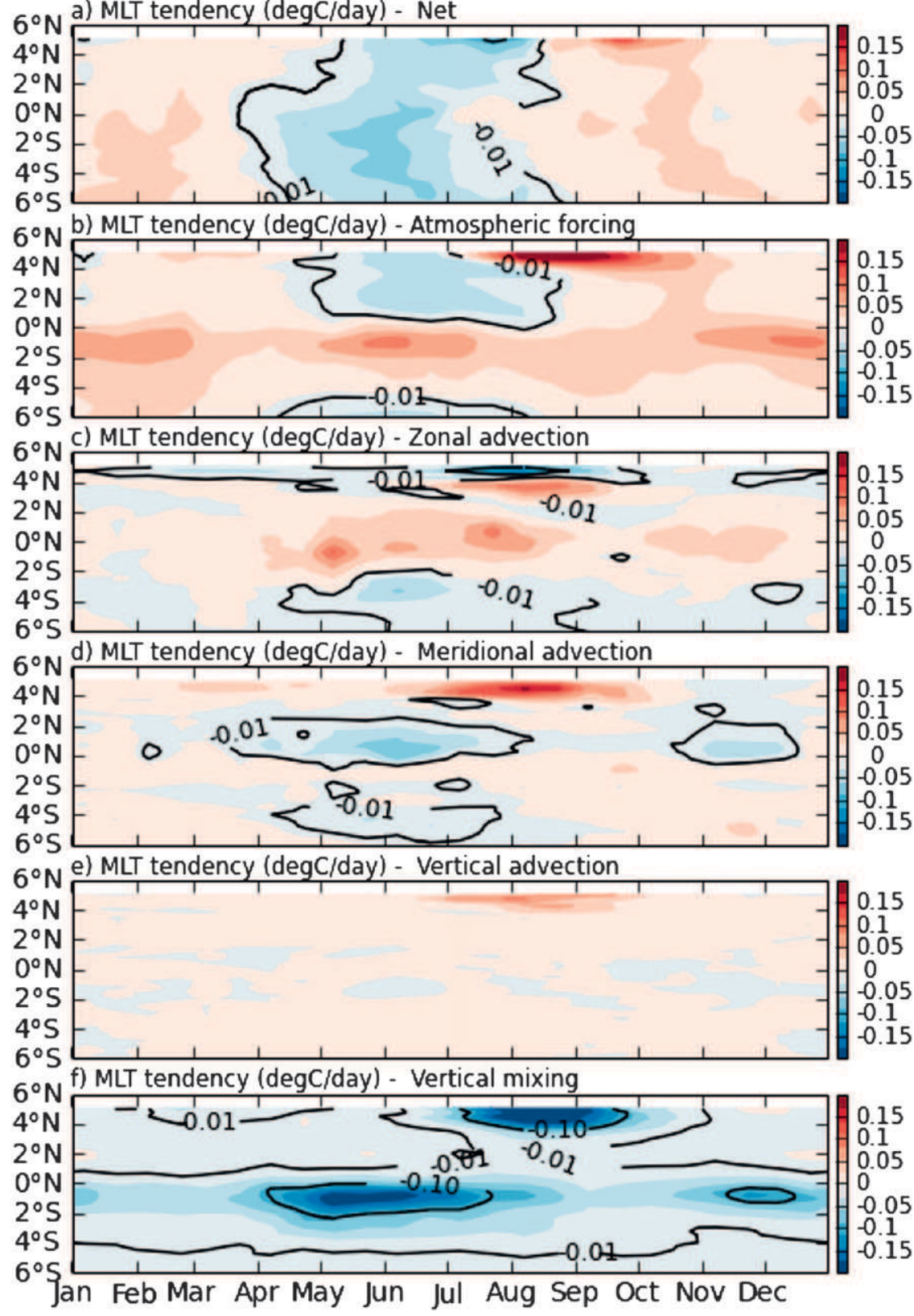

FIG. 2. Time-latitude climatological distribution of the main contributors to the mixed-layer heat budget at $5^{\circ} \mathrm{W}$ : (a) net mixed-layer temperature tendency, and tendencies due to (b) atmospheric forcing, (c) zonal advection, (d) meridional advection, (e) vertical advection, and (f) turbulent heat flux ZDF [see Eq. (2) of Vialard et al. (2001) for details]. Contributions of lateral diffusion and of entrainment at the mixed-layer base are negligible and not shown here. The mixed-layer depth is defined as the depth where the density increase compared to density at $10 \mathrm{~m}$ equals $0.03 \mathrm{~kg} \mathrm{~m}^{-3}$. Units are in degrees Celsius per day, and contours correspond to $0.01^{\circ}$ and $0.1^{\circ} \mathrm{C}$ day $^{-1}$ cooling tendency. The considered period is 2001-06.

vertical gradient of potential temperature. To allow a precise evaluation of $Q_{\mathrm{zdf}}$, the term in the integral is computed online. In the following, the vertical structure and time variability of this term is analyzed, along with its value $Q_{\mathrm{zdfML}}$ at the base of the mixed layer and its contribution ZDF to the surface mixed-layer heat budget (see legend of Fig. 2).

Numerical results are compared with satellite SSTs from the Tropical Rainfall Measuring Mission (TRMM) Microwave Imager (TMI), available from 1998 with 


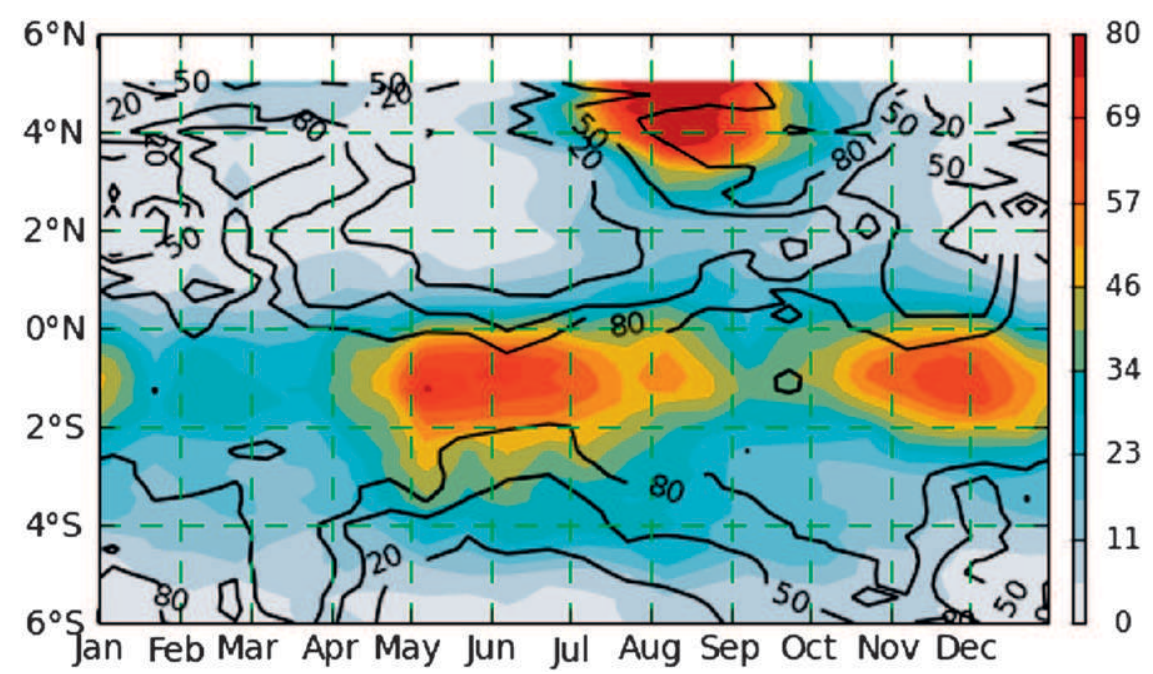

FIG. 3. Time-latitude diagram at $5^{\circ} \mathrm{W}$ of $Q_{\text {zdfML }}$ (W m ${ }^{-2}$, color). The contribution of ZDF compared to the sum of the other cooling contributions is indicated with the $20 \%, 50 \%$, and $80 \%$ contours. The considered period is $2001-06$.

a $1 / 4^{\circ}$ horizontal resolution. Chl-a concentrations are from the monthly level-3 gridded GlobColour product from the European Space Agency project, with $1 / 4^{\circ}$ resolution. Since Chl-a time series in the Gulf of Guinea show significant gaps due to cloud cover, only the climatological seasonal cycle over the period 1998-2009 will be addressed in the paper.

\section{Results}

In satellite observations, the lowest values and largest amplitude of the SST seasonal signal occur south of the equator (Figs. 1a,b). The cold tongue starts to form in late April and reaches its largest extension in August. Then it merges south of $4^{\circ} \mathrm{S}$ with cold waters as a result of Southern Hemisphere coastal upwelling and austral winter cooling (Fig. 1a; Carton and Zhou 1997). An intense SST front is present north of the cold tongue, being progressively shifted from $1^{\circ} \mathrm{N}$ in the center of the basin to $1^{\circ} \mathrm{S}$ close to the African coast. These features and the amplitude of the seasonal cycle are reproduced by the model (Figs. 1a,b). There is a secondary SST minimum along the northern coast during July-August (Figs. 1a,b), which is consistent with in situ observations (Picaut 1983). Note that the equatorial cold tongue is about $1^{\circ} \mathrm{C}$ too warm when compared to observed SSTs, but this is a common failure of ocean models.

The temperature tendency at the surface results from imbalance between warming and cooling processes. Following Peter et al. (2006), Fig. 2 presents the seasonal variations of the contribution of atmospheric forcing, vertical and lateral mixing, advection, and entrainment to mixed-layer temperature tendency (see legend of Fig. 2 for details). The vertical mixing (ZDF) mostly acts to cool the mixed layer (Fig. 2f). Its contribution to the cooling relative to the other processes is quantified and shown with contours in Fig. 3 . At $5^{\circ} \mathrm{W}$, the contribution of $\mathrm{ZDF}$ is higher than $50 \%$ between the equator and $4^{\circ} \mathrm{S}$ all year long, exceeding $80 \%$ in the $2^{\circ} \mathrm{S}-0^{\circ} \mathrm{N}$ band. Along the northern coast, it is predominant twice a year in boreal winter and summer.

The quantity $Q_{\text {zdfML }}$ in the Gulf of Guinea is maximum near the equator and along the northern coast (Fig. 3 ). Along the equator it peaks in May-June with values up to $70 \mathrm{~W} \mathrm{~m}^{-2}$ and coincides with the period of both strongest ZDF (Fig. 2f) and highest cooling (Fig. 1a). This is in agreement with estimates by Foltz et al. (2003) and highlights the important role of vertical mixing for the seasonal surface cooling. A secondary peak occurs in November-December (Fig. 2f), but its impact on the SST tendency term is weak (Fig. 2a) because of intense atmospheric warming during this period (Fig. 2b). Although $Q_{\mathrm{zdfML}}$ is lower between $2^{\circ} \mathrm{S}$ and $4^{\circ} \mathrm{S}$, the contribution of ZDF to the mixed-layer cooling remains higher than $50 \%$ and the net surface cooling is strong. In this latitudinal range, an additional contributor to the mixed-layer cooling is the poleward export of cold waters from the equator (Fig. 2d). At the northern coast, both $\mathrm{ZDF}$ and $Q_{\mathrm{zdfML}}$ are strongest from mid-July to mid-September, coinciding with the period of lowest SSTs. This coastal cooling adds to, and follows, a largescale cooling of the northern part of the Gulf of Guinea, driven by air-sea heat fluxes and occurring in May-June (Fig. 2b). A weak and second intensification 

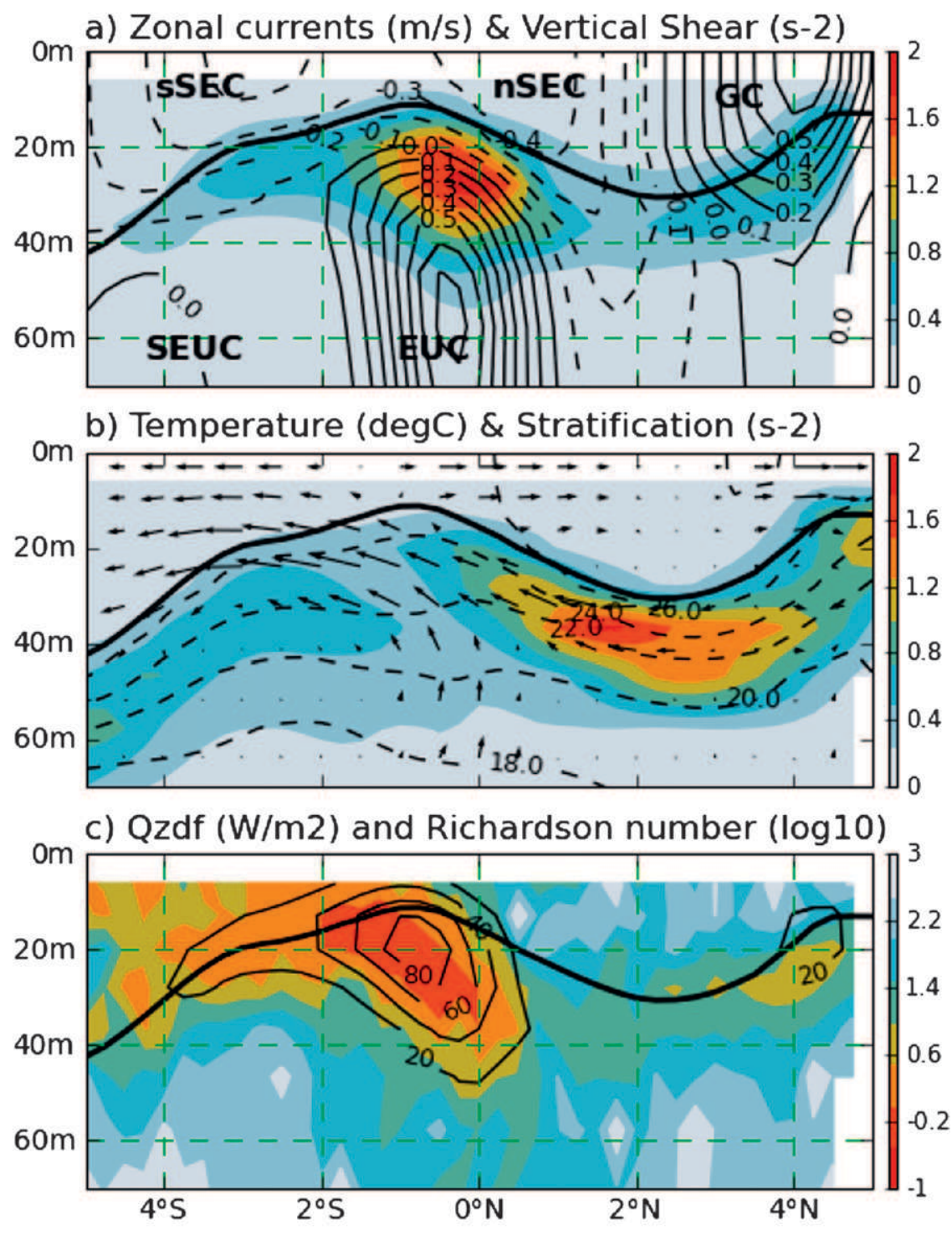

v: $0.1 \mathrm{~m} / \mathrm{s} \rightarrow \quad$ w: $2.1 \mathrm{~m} /$ day $\longrightarrow$

FIG. 4. Mean meridional sections at $5^{\circ} \mathrm{W}$ of model fields during May-August. The thick black line indicates the mixed-layer depth. (a) Zonal currents ( $\mathrm{m} \mathrm{s}^{-1}$, contours) and vertical shear squared due to both zonal and meridional currents (colors); (b) temperature $\left({ }^{\circ} \mathrm{C}\right.$, dotted contours), stratification ( $\mathrm{s}^{-2}$, colors), and meridional and vertical components of the mean current (vectors); (c) $Q_{\mathrm{zdf}}$ (contours) and Richardson number (colors, in logarithmic scale). The main currents of the region are shown: the Equatorial Undercurrent (EUC), the southern and northern South Equatorial Currents (sSEC and nSEC), the Guinea Current, and the South Equatorial Undercurrent (SEUC). In terms of position and intensity of the currents, this section is in agreement with observations at $10^{\circ} \mathrm{W}$ in Kolodziejczyk et al. (2009).

of ZDF and $Q_{\text {zdfML }}$ occurs close to the coast in FebruaryMarch.

To investigate the processes that govern $Q_{\mathrm{zdfML}}$, we now examine mean meridional sections of model results at $5^{\circ} \mathrm{W}$ in May-August (Fig. 4). There is a good agreement between high values of $Q_{\text {zdf }}$ and low values of $\mathrm{Ri}=N^{2} / S^{2}$ (Fig. 4c), with $N^{2}$ being the Brunt-Vaïsälä frequency and $S^{2}$ the vertical shear squared. This indicates that $Q_{\mathrm{zdf}}$ is driven by the stability of the sheared flow. The highest values of $Q_{\mathrm{zdf}}\left(>80 \mathrm{~W} \mathrm{~m}^{-2}\right)$ occur between $1^{\circ} \mathrm{S}$ and $0.5^{\circ} \mathrm{S}$ (Fig. 4c), just above the core of the Equatorial Undercurrent (EUC), where the vertical shear is maximum (Fig. 4a). Strong shear also occurs farther south because of the presence of the southern South 
a) Qzdf at the ML base $(\mathrm{W} / \mathrm{m} 2)$
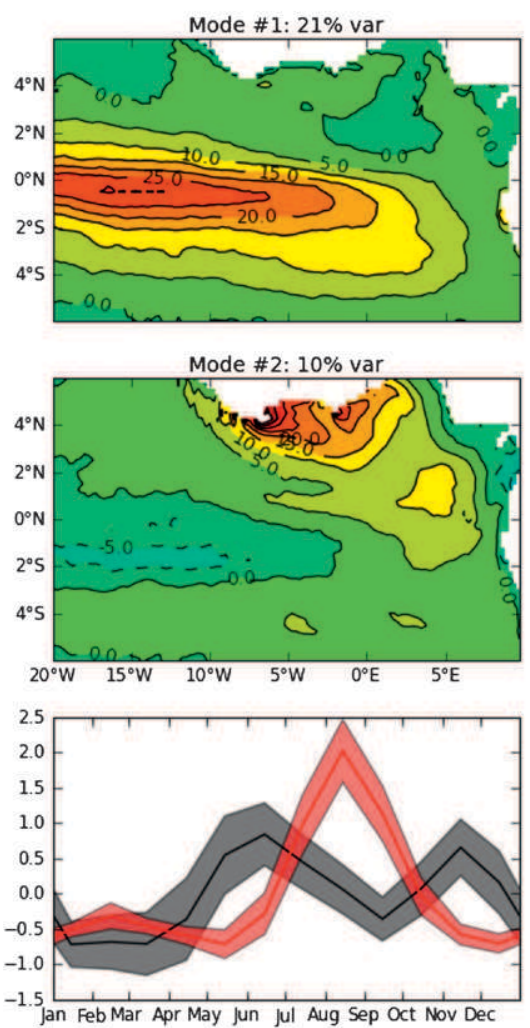

b) Vertical shear (s-2)
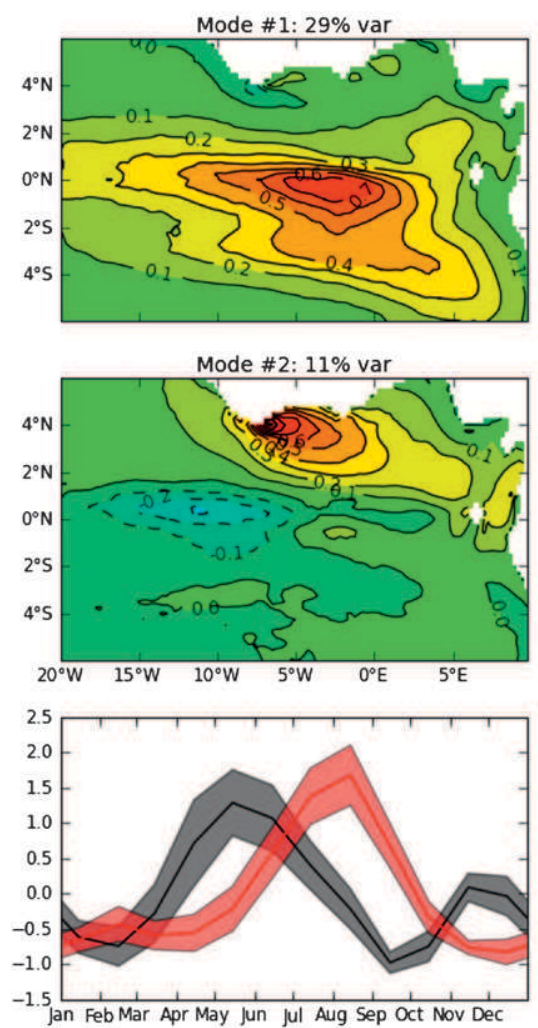

c) Zonal surface currents $(\mathrm{m} / \mathrm{s})$
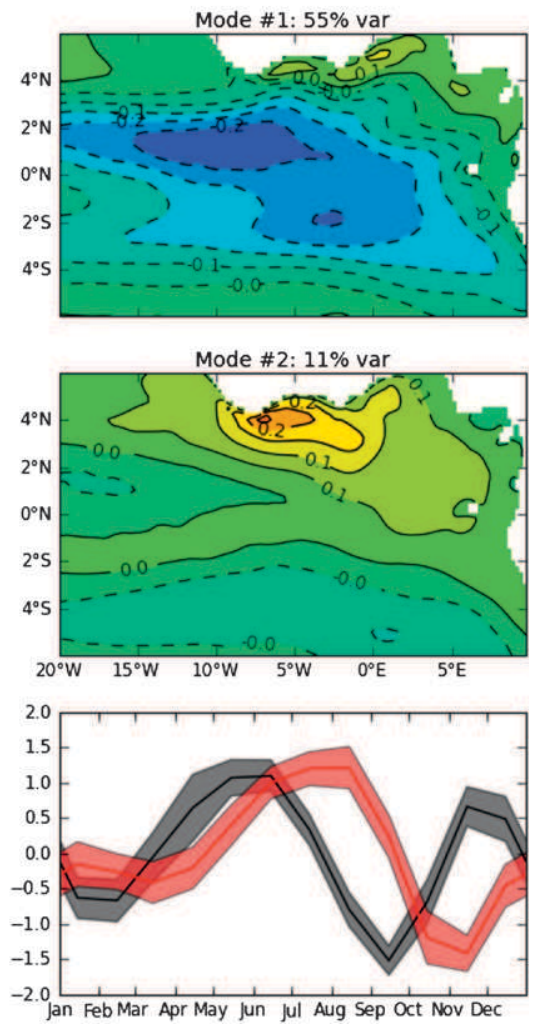

FIG. 5. EOF analysis of (a) $Q_{\text {zdfML }}\left(\mathrm{W} \mathrm{m} \mathrm{m}^{-2}\right)$, (b) vertical shear $\left(\mathrm{s}^{-2}\right)$, and (c) surface zonal currents $\left(\mathrm{m} \mathrm{s}^{-1}\right)$. The vertical shear is computed as the maximum value of $u_{z}^{2}+v_{z}^{2}$ in the upper $100 \mathrm{~m}$. Bottom diagrams show monthly composite time series of modes 1 (black) and 2 (red). Shading indicates the standard deviation with respect to the monthly mean values. EOFs have been computed using daily model outputs from January 2001 to December 2006.

Equatorial Current (sSEC), allowing significant values of $Q_{\mathrm{zdf}}\left(>20 \mathrm{~W} \mathrm{~m}^{-2}\right)$ to span until $4^{\circ} \mathrm{S}$. Coinciding with low shear and high stratification, $Q_{z \mathrm{df}}$ is low in the $1^{\circ}-3^{\circ} \mathrm{N}$ band (Fig. 4b). Along the northern coast, the shear at the base of the Guinea Current is strong. This leads to high $Q_{\text {zdf }}$ near $4^{\circ} \mathrm{N}$, just below the core of the current (Figs. 4a,c).

The seasonal and spatial variability of $Q_{\mathrm{zdfML}}$ is captured with an empirical orthogonal function (EOF) analysis (Fig. 5a). The first mode of $Q_{\text {zdfML }}$ explains $21 \%$ of the variance, is maximum at the equator, extends to the south eastward of $5^{\circ} \mathrm{W}$, and peaks in May-June and November-December (Fig. 5a). In terms of spatial and seasonal variability, there is a good agreement between this mode and the first mode of both vertical shear (Fig. $5 b$ ) and zonal surface currents (Fig. 5c). Mode 1 of zonal surface currents matches the horizontal structure of the southern and northern South Equatorial Current (nSEC) as inferred from drifter observations (Lumpkin and Garzoli 2005). This suggests that the seasonal westward intensification of the northern and southern branches of the SEC drives the vertical shear and thus the formation of the cold tongue. The sSEC starts closer to the African coast than the nSEC. This partly explains why high amplitudes of mode 1 of $Q_{\mathrm{zdfML}}$ extend more eastward at $4^{\circ} \mathrm{S}$ than at the equator.

The second modes of $Q_{\mathrm{zdfML}}$, vertical shear and surface currents, are maximum at the location of the Guinea Current, and all show one seasonal peak in August. Therefore, this suggests that the intensification of the Guinea Current in July-August drives the peak of $Q_{\text {zdfML }}$ along the northern coast during the same period. It is worth mentioning that a similar EOF calculation was performed on monthly climatological $Q_{\mathrm{zdfML}}$ (not shown). The first two EOF modes show the same spatial and temporal characteristics as in Fig. 5a, but now they respectively explain $46 \%$ and $38 \%$ of the variance.

We now examine the possibility that turbulent mixing is partly responsible for the seasonal cycle and spatial structure of Chl-a. As for $Q_{\text {zdfML }}$, the highest concentrations of Chl-a in the open ocean occur from $20^{\circ}$ to $10^{\circ} \mathrm{W}$ and between $1^{\circ} \mathrm{S}$ and the equator, with 

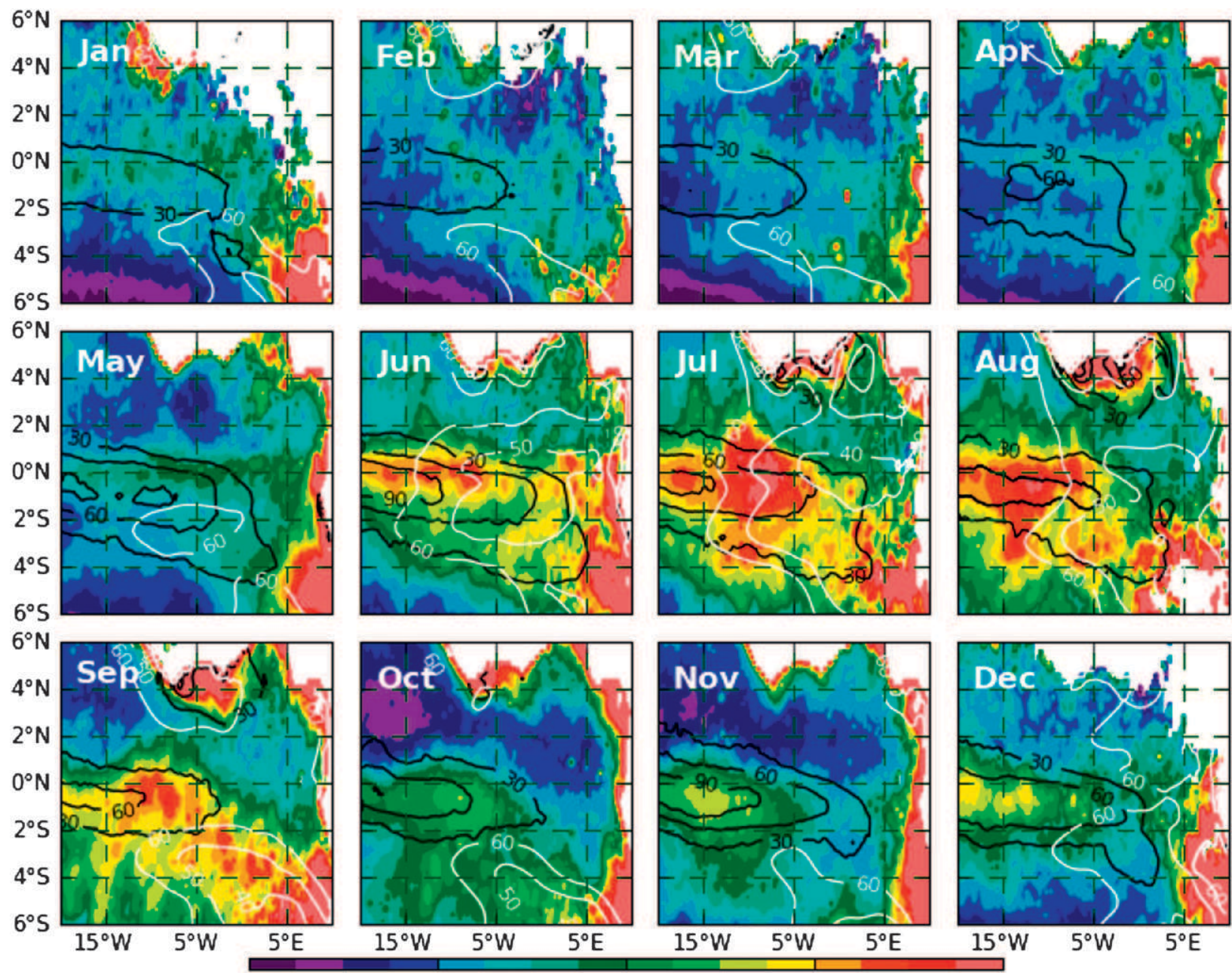

$-1$
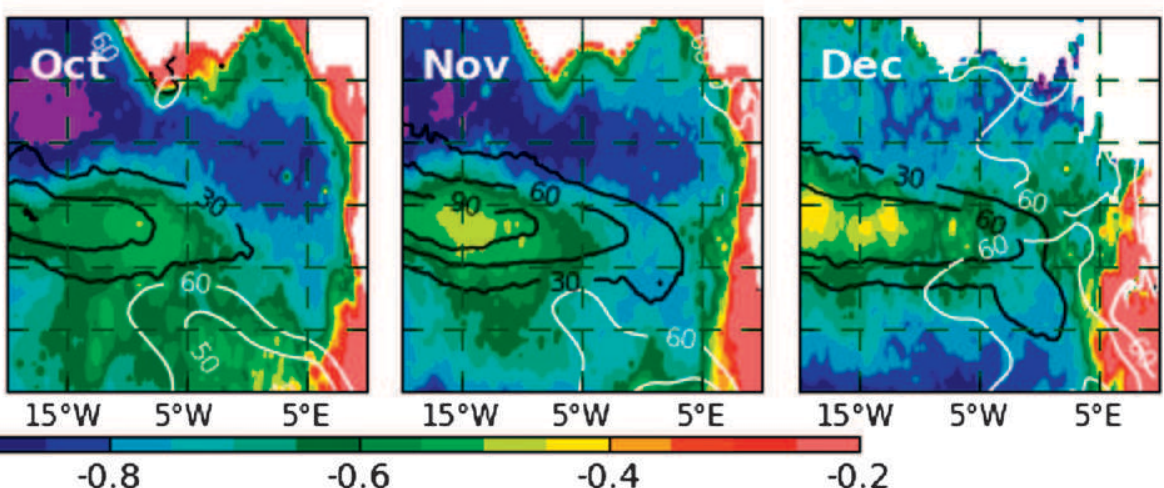

FIG. 6. Monthly composite maps of Chl-a concentrations for case-1 waters for the period 1998-2009. Climatological monthly horizontal distribution of $Q_{\mathrm{zdfML}}$ and $20^{\circ} \mathrm{C}$ isotherm depth from the model are superimposed respectively in black contours (30,60, 90, and $120 \mathrm{~W} \mathrm{~m}^{-2}$ ) and white contours (40,50, and $\left.60 \mathrm{~m}\right)$.

a main seasonal peak in June-August and a secondary peak in December (Fig. 6). Along the northern coast, concentrations are high in August-September. In these two regions, the spatial structure of Chl-a is correlated to $Q_{\text {zdfML }}$, with a 1 -month lag. At $4^{\circ} \mathrm{S}$, we identify a local maximum that merges at $5^{\circ} \mathrm{E}$ with a pattern of high Chl-a associated with Congo River plume and coastal upwelling (Signorini et al. 1999).

\section{Discussion and summary}

Vertical mixing is shown to be the major factor controlling the timing and spatial distribution of the seasonal cooling in the Gulf of Guinea. Patterns of cooling have large zonal coherence. This is due to large-scale variations of the sSEC, nSEC, and Guinea Current, which modulate locally the vertical shear at the subsurface and thus control the turbulent exchanges.

Semiannual variation of the nSEC is shown to drive the semiannual cycles of $Q_{\mathrm{zdfML}}$ close to the equator. Nevertheless, the maximum of cooling does not occur at $1^{\circ} \mathrm{N}$ where the nSEC is maximum but at $1^{\circ} \mathrm{S}$. The reasons are that velocities in the core of the EUC 1) are intense and provide an almost continuous background shear above its core and 2) present low seasonal modulation (Arhan et al. 2006), so they are not expected to drive the $Q_{\text {zdfML }}$ seasonal cycle. In agreement with Richardson and McKee (1984), the nSEC in the model shows large semiannual variation whereas the SSEC is dominated by an annual signal (not shown). This explains that between $1^{\circ}$ and $4^{\circ} \mathrm{S}, Q_{\mathrm{zdfML}}$ during November-December is not as strong as during boreal summer (Fig. 3). 
The SST in the Gulf of Guinea shows a sharp northsouth asymmetry all the year round. We identify three mechanisms that might contribute to the shift of the cooling south of the equator. First, vertical velocities at $5^{\circ} \mathrm{W}$ in the model are maximum at $1^{\circ} \mathrm{S}$ (Fig. $4 \mathrm{~b}$ ). This corresponds to the asymmetric upwelling proposed by Rhein et al. (2010): southerly winds induce a northward surface flow on the equator that needs to be balanced by upwelling south of the equator. Second, the EUC is also shifted to $1^{\circ} \mathrm{S}$. Since the velocity shear is maximum above its core, $Q_{\mathrm{zdf}}$ is maximum at this latitude (Figs. $4 a, c)$. Third, the sSEC induces off equator a strong vertical mixing that is shown to be the main contributor to the southward extension of the cold tongue (Figs. 3 and $4 \mathrm{c}$ ). Note that the $Q_{\mathrm{zdfML}}$ maximum driven by the sSEC better explains the high upwelling rates inferred from helium disequilibrium by Rhein et al. (2010) at $4^{\circ} \mathrm{S}, 10^{\circ} \mathrm{W}$ than the asymmetrical upwelling mechanism, which should only be valid close to the equator.

North of the Gulf of Guinea, Bakun (1978) found a correlation between intensification of the Guinea Current and local cooling. The mechanism first proposed was that geostrophic adjustment caused a shoaling of the thermocline toward the coast. But numerical simulation of such process, in a model with constant vertical diffusion coefficient, produced insignificant upwelling along the northern coast (Philander 1979). Our results fill the gap between these studies: most of the cooling is due to enhanced $Q_{\mathrm{zdfML}}$ when the Guinea Current is intense. Interestingly, there is a 3-month lag between the two peaks along the northern coast and the peaks at the equator. This suggests a connection with equatorial dynamics as already proposed by Picaut (1983).

Seasonal Chl-a concentrations show a maximum at the equator all year round. So a process continuously brings subsurface waters to the mixed layer. This is achieved by vertical mixing above the EUC core. In June-July, there is a clear north-south asymmetry of Chl-a, which better matches the spatial structure of $Q_{\mathrm{zdfML}}$ in May-June than that of the $20^{\circ} \mathrm{C}$ isotherm during this period (Fig. 6). The depth of the $20^{\circ} \mathrm{C}$ isotherm is shallowest close to the African coast, whereas Chl-a is highest between $20^{\circ}$ and $10^{\circ} \mathrm{W}$. So the depth of the thermocline might not be the primary driver for Chl-a, as often proposed. The occurrence of a secondary maximum of Chl-a at the equator in December, despite no net surface cooling during this period, is in agreement with the occurrence of a secondary maximum of $Q_{\text {zdfML }}$.

This study is the first to our knowledge to point out the importance of mixing induced by the SSEC for cooling and nutrient flux in the tropical Atlantic. Such mechanism goes against the classical view that cool waters and high Chl-a concentrations in the southeastern basin are due to offshore advection of the coastal upwelling. The implications of these results for understanding SST interannual variability SST in the cold tongue deserve further attention.

Acknowledgments. This study was supported by the Institut de Recherche pour le Développement. TMI data were produced by Remote Sensing Systems. Chl-a data were produced by ACRI-ST GlobColour service. We acknowledge the provision of supercomputing facilities by the CICESE (Conacyt project SEP-2003C02-44534). The regional configuration was set up in cooperation with the DRAKKAR project.

\section{REFERENCES}

Arhan, M., A. M. Tréguier, B. Bourlès, and S. Michel, 2006: Diagnosing the annual cycle of the Equatorial Undercurrent in the Atlantic Ocean from a general circulation model. J. Phys. Oceanogr., 36, 1502-1522.

Bakun, A., 1978: Guinea Current upwelling. Nature, 271, $147-150$

Barnier, B., and Coauthors, 2006: Impact of partial steps and momentum advection schemes in a global ocean circulation model at eddy permitting resolution. Ocean Dyn., 56, 543-567, doi:10.1007/s10236-006-0082-1.

Blanke, B., and P. Delecluse, 1993: Variability of the tropical Atlantic Ocean simulated by a general circulation model with two different mixed-layer physics. J. Phys. Oceanogr., 23, 1363-1388.

Brodeau, L., B. Barnier, A. Treguier, T. Penduff, and S. Gulev, 2010: An ERA40-based atmospheric forcing for global ocean circulations models. Ocean Modell., 31, 88-104.

Carton, J. A., and Z. Zhou, 1997: Annual cycle of sea surface temperature in the tropical Atlantic Ocean. J. Geophys. Res., 102 (C13), 27 813-27 824.

Foltz, G. R., S. A. Grodsky, J. A. Carton, and M. J. McPhaden, 2003: Seasonal mixed layer heat budget of the Tropical Atlantic Ocean. J. Geophys. Res., 108, 3146, doi:10.1029/ 2002JC001584.

Grodsky, S. A., J. A. Carton, and C. R. McClain, 2008: Variability of upwelling and chlorophyll in the equatorial Atlantic. Geophys. Res. Lett., 35, L03610, doi:10.1029/2007GL032466.

Helber, R. W., R. H. Weisberg, F. Bonjean, E. S. Johnson, and G. S. E. Lagerloef, 2007: Satellite derived surface current divergence in relation to tropical Atlantic SST and wind. J. Phys. Oceanogr., 37, 1357-1375.

Kolodziejczyk, N., B. Bourlès, F. Marin, J. Grelet, and R. Chuchla, 2009: Seasonal variability of the Equatorial Undercurrent at $10^{\circ} \mathrm{W}$ as inferred from recent in situ observations. J. Geophys. Res., 114, C06014, doi:10.1029/ 2008JC004976.

Lumpkin, R., and S. L. Garzoli, 2005: Near-surface circulation in the tropical Atlantic. Deep-Sea Res. I, 52, 495-518.

Madec, G., 2008: NEMO ocean engine. Note du Pôle de Modélisation No. 27, Institut Pierre-Simon Laplace (IPSL), 209 pp.

Okumura, Y., and S.-P. Xie, 2006: Some overlooked features of tropical Atlantic climate leading to a new Niño-like phenomenon. J. Climate, 19, 5859-5874. 
Peter, A.-C., M. Le Hénaff, Y. du Penhoat, C. E. Menkes, F. Marin, J. Vialard, G. Caniaux, and A. Lazar, 2006: A model study of the seasonal mixed layer heat budget in the equatorial Atlantic. J. Geophys. Res., 111, C06014, doi:10.1029/2005JC003157.

Philander, S. G. H., 1979: Upwelling in the Gulf of Guinea. J. Mar. Res., 37, 23-33.

Picaut, J., 1983: Propagation of the seasonal upwelling in the eastern equatorial Atlantic. J. Phys. Oceanogr., 13, 18-37.

Rhein, M., M. Dengler, J. Sültenfuss, R. Hummels, S. Hüttl-Kabus, and B. Bourlès, 2010: Upwelling and associated heat flux in the equatorial Atlantic inferred from helium isotope disequilibrium. J. Geophys. Res., 115, C08021, doi:10.1029/2009JC005772.
Richardson, P. L., and T. K. McKee, 1984: Average seasonal variation of the Atlantic equatorial currents from historical ship drifts. J. Phys. Oceanogr., 14, 1226-1238.

Signorini, S. R., R. G. Murtugudde, C. R. McClain, J. R. Christian, J. Picaut, and A. J. Busalacchi, 1999: Biological and physical signatures in the tropical and subtropical Atlantic. J. Geophys. Res., 104, 18 367-18 382.

Vialard, J., C. Menkes, J. P. Boulanger, P. Delecluse, E. Guilyardi, M. J. McPhaden, and G. Madec, 2001: A model study of oceanic mechanisms affecting equatorial Pacific sea surface temperature during the 1997-98 El Niño. J. Phys. Oceanogr., 31, 1649-1675. 